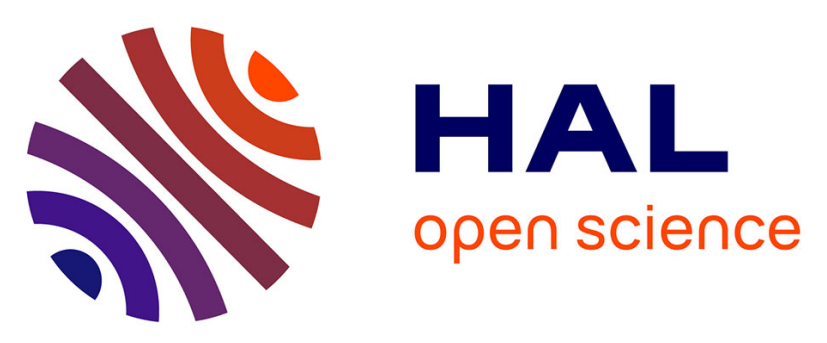

\title{
How to determine the parameters of polymer crystallization for modeling the injection-molding process?
}

Séverine A.E. Boyer, Luisa Silva, Mounia Gicquel, Samuel Devisme, Jean-Loup Chenot, Jean-Marc Haudin

\section{To cite this version:}

Séverine A.E. Boyer, Luisa Silva, Mounia Gicquel, Samuel Devisme, Jean-Loup Chenot, et al.. How to determine the parameters of polymer crystallization for modeling the injection-molding process? 11th ESAFORM Conference on Material Forming, Apr 2008, Lyon, France. pp.Pages 599-602, 10.1007/s12289-008-0327-2 . hal-00510263

\section{HAL Id: hal-00510263}

https: / hal-mines-paristech.archives-ouvertes.fr/hal-00510263

Submitted on 18 Aug 2010

HAL is a multi-disciplinary open access archive for the deposit and dissemination of scientific research documents, whether they are published or not. The documents may come from teaching and research institutions in France or abroad, or from public or private research centers.
L'archive ouverte pluridisciplinaire HAL, est destinée au dépôt et à la diffusion de documents scientifiques de niveau recherche, publiés ou non, émanant des établissements d'enseignement et de recherche français ou étrangers, des laboratoires publics ou privés. 


\title{
How to determine the parameters of polymer crystallization for modeling the injection-molding process?
}

\author{
S.A.E. Boyer ${ }^{1}$, L. Silva ${ }^{1}$, M. Gicquel ${ }^{1}$, S. Devisme ${ }^{2}$, J.-L. Chenot ${ }^{1}$, J.-M. Haudin ${ }^{1}$ \\ ${ }^{1}$ CEMEF/ENSMP, 1 rue Claude Daunesse \\ 06904 Sophia Antipolis, France \\ URL: www-cemef.cma.fr \\ e-mail:Severine.Boyer@ensmp.fr ; Luisa.Silva@ensmp.fr \\ Jean-Loup.Chenot@ensmp.fr; Jean-Marc.Haudin@ensmp.fr
}

${ }^{2}$ ARKEMA, route du Rilsan

27470 Serquigny, France

URL: www.arkema.fr

e-mail:SSamuel.Devisme@arkemagroup.com

\begin{abstract}
To understand the relationship between 'polymers-processing conditions-structures-properties', crystallization is one of the major concerned phenomena. A general crystallization model derived from Avrami's work has been developed at CEMEF and implemented into a 3D finite element code for injectionmolding named Rem $3 \mathrm{D}^{\mathbb{R}}$. It gives a precise description of the crystallization event, allows the determination of morphological features, but it requires a reliable determination of the crystallization parameters. The experimental procedures adopted to capture relevant experimental parameters are presented. The determination of overall kinetics, density of potential nuclei with activation frequency of nuclei into crystalline entities, and growth rate is carried out with polarized optical microscopy (POM) and is supplemented by small angle light scattering (SALS). The treatment of data is performed by a classical method or using an inverse genetic algorithm method to extract the parameters necessary to our model. The 2D simulation of the crystallization, illustrated with $\operatorname{Rem}_{3} \mathrm{D}^{\circledR}$, reproduces the experimental reality quite accurately, in the case of an isothermal and static crystallization. This is applied to two polymers, an isotactic homopolymer polypropylene iPP and a polyether-block amide PEBAX ${ }^{\circledR}$.
\end{abstract}

Key words: Liquid/Solid Transition, Polymers, Modeling, Simulation, Injection-Molding.

\section{INTRODUCTION}

The correlation between phase-transitions of polymers and extreme and complex conditions is of great technological and academic interest [1]. In this field, many polymer products are manufactured by injection-molding, a process that has the potential to mass-produce with complex shape. End-use properties of the final injected parts are directly related to the final micro-structural and hierarchic organization of macromolecules, i.e. spherulite, shish-kebab, transcrystallinity zone and teardropshaped spherulite.

To understand the micro-structural development, it is necessary to describe the liquid/solid transition under complex and coupled thermo-mechanical conditions.

Crystallization in molten polymers results from the nucleation event, in a more or less sporadic manner, and the growth of nuclei into crystalline entities, which spread over the entire volume at the end of the transformation. To describe the overall kinetics during the primary crystallization under quiescent, isothermal, conditions Avrami's model is the most widely used, partly because of its firm theoretical basis leading to analytical mathematical equations [2-5].

This paper reports a number of aspects that include the following: the description of the methods for obtaining and treating the key parameters needed in crystallization models, the optimization of the data by the inverse genetic algorithm method, the introduction of the models into a 3D finite element code. A discussion is presented that provides insight into the benefit of using different techniques and analysis methods in the investigation of polymer crystallization. 


\section{THEORETICAL BACKGROUND}

\subsection{Avrami macro-kinetic model}

Starting from Avrami's hypotheses, we recently proposed a new numerical approach $[4,5]$. Original Avrami's theory was extended to treat nonisothermal crystallization. The key equations of crystallization were cast into a general differential system that is integrated numerically. They underline the influence of the processing conditions, namely temperature with cooling-rate and shear rate, on: the transformed volume fraction, the density of potential nuclei together with the activation frequency of nuclei into crystalline entities, the growth rate of entities, and the morphological features.

\subsection{Set of differential equations, Key parameters}

The set of differential equations involve the identification of three kinetic parameters, namely $\mathrm{N}_{0}(\mathrm{~T}(\mathrm{t})), \mathrm{q}(\mathrm{T}(\mathrm{t}))$ and $\mathrm{G}(\mathrm{T}(\mathrm{t}))$. The term $\mathrm{N}_{0}(\mathrm{~T}(\mathrm{t}))$ is the initial density of potential nuclei, $q(T(t))$ the activation frequency of these nuclei and $G(T(t))$ the growth rate of the semi-crystalline entities, which are supposed to be disks (discoids) in 2D and spherulites in 3D. The kinetic parameters are defined as a function of temperature $\mathrm{T}$ as shown in the system (1) of equations below.

$$
\begin{aligned}
& N_{0}=N_{00} \exp \left(-N_{01}\left(T-T_{0}\right)\right) \\
& q=q_{0} \exp \left(-q_{1}\left(T-T_{0}\right)\right) \\
& G=G_{0} \exp \left(-G_{1}\left(T-T_{0}\right)\right)
\end{aligned}
$$

The coefficients $\left[\mathrm{N}_{00}, \mathrm{~N}_{01}, \mathrm{q}_{0}, \mathrm{q}_{1}, \mathrm{G}_{0}, \mathrm{G}_{1}\right]$ are determined directly from experiments or calculated by the genetic algorithm inverse method.

\subsection{Simulation code}

The crystallization laws were implemented into Rem3D ${ }^{\circledR}$, a 3D finite-element code written in $\mathrm{C}++$. It allows us to reproduce the crystallization phenomena which occur during the injection molding process, with the prediction of the distribution of the transformed fraction and of the number of potential and activated nuclei [6]. The numerical resolution is based on a Runge-Kutta Stabilized Galerkin integration scheme.

\section{EXPERIMENTAL}

\subsection{Materials}

The materials used are grades for injection molding. An isotactic homopolymer polypropylene iPP (molar mass: $\mathrm{Mn}=42500 \mathrm{~g} / \mathrm{mol}, \mathrm{Mw}=213000 \mathrm{~g} / \mathrm{mol}$ ) was supplied by ATOFINA Company (France) under the reference 3250 MR1. A poly(ether-block amide) PEBAX $^{\circledR}$ thermoplastic elastomer based on nylon 12 and poly(tetramethylene oxide) was investigated. It was obtained from ARKEMA (France).

Thin layers of polymers were pushed on an optical cover glass in a transparent hot-stage. The molten polymer was maintained at $210{ }^{\circ} \mathrm{C}$ during $5 \mathrm{~min}$ and cooled at $-10{ }^{\circ} \mathrm{C} \cdot \mathrm{min}^{-1}$ down to the crystallization temperatures, for isothermal studies, or at various cooling-rates down to the end of crystallization, for non-isothermal studies.

\subsection{Techniques}

\section{2.a Polarizing Optical Microscopy (POM)}

The crystallization events and morphological features were observed under crossed polarizers with a polarizing LEICA-DMRX microscope (Leicamicrosystemes, France).

\section{2.b Small-Angle Light Scattering (SALS)}

SALS patterns were collected by using a heliumneon polarized laser. The wave length of the laser is $\lambda=0.6328 \mu \mathrm{m}$. The parallel, vertically polarized light beam radiated by the laser is scattered by the crystallizing polymer film and then analyzed by a crossed polarizer.

\section{RESULTS AND DISCUSSIONS}

In $3 \mathrm{D}$, it is difficult to accurately determine the three key parameters of polymer crystallization necessary for modeling the injection-molding process. The strategy is to identify the parameters in $2 \mathrm{D}$, and then to translate the information into $3 \mathrm{D}$.

\subsection{Overall kinetics and Kinetic parameters}

\section{Overall kinetics}

The overall kinetics can be deduced from light depolarization integration of the POM images, which is proportional to the transformed volume fraction. Knowing $\mathrm{N}_{0}$ and $\mathrm{G}(\mathrm{T})$ from the POM 
images analysis (see after), the overall kinetics can also be calculated from Avrami's equation (2) in 2D growth and instantaneous nucleation.

$$
\alpha(T, t)=1-\exp \left(-\pi N_{0} G(T)^{2} t^{2}\right)
$$

The overall kinetics, deduced from light depolarization integration and from Avrami's equation, was plotted as a function of time. Figure 1 shows the well agreement between the two methods of determination. It implies that light depolarization measurements can be used in the determination of the overall kinetics when the kinetic parameters $\mathrm{N}_{0}(\mathrm{~T}(\mathrm{t}))$ and $\mathrm{G}(\mathrm{T}(\mathrm{t})$ ) cannot be determined directly from the optical observations.

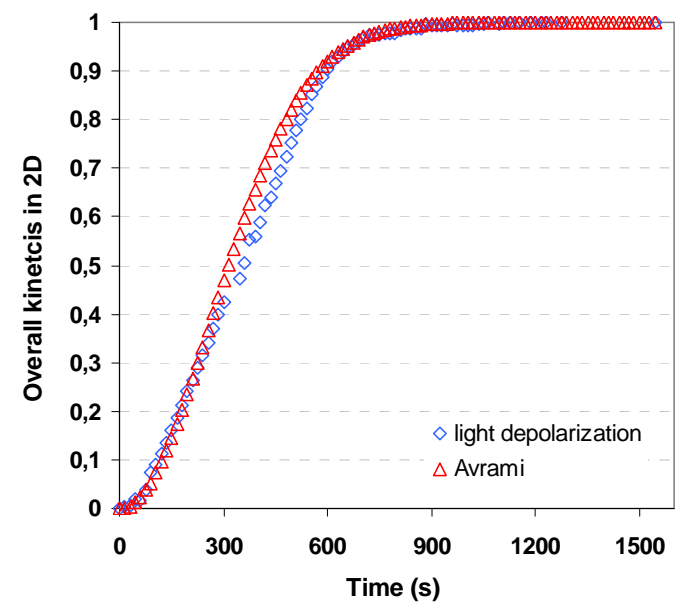

Fig. 1. Overall kinetics in 2D (5 $\mu \mathrm{m}$-thick layer $)$ of iPP at $126^{\circ} \mathrm{C}$.

\section{Kinetic parameters $N_{0}(T(t)), q(T(t))$ and $G(T(t))$}

Kinetic parameters are issued from the analysis of each POM image of the time evolution of $\mathrm{N}_{\mathrm{a}}(\mathrm{T})=$ $\mathrm{f}(\mathrm{t})$, while crystallization occurs. $\mathrm{N}_{\mathrm{a}}(\mathrm{T}(\mathrm{t}))$ is the number of activated nuclei.

Nucleation parameters $\mathrm{N}_{0}(\mathrm{~T})$ and $\mathrm{q}(\mathrm{T})$ are deduced from the number of spherulites centers $\mathrm{N}_{\mathrm{a}}(\mathrm{T}(\mathrm{t})$ ) observed. The final number $\mathrm{N}_{\mathrm{a}}(\mathrm{T})$ is approximated to $\mathrm{N}_{0}(\mathrm{~T}) \quad(\alpha(\mathrm{t})=1)$. $\mathrm{q}(\mathrm{T})$ is calculated during the first steps of nucleation. Nevertheless $q(T)$ is relatively difficult to estimate. Knowing $\mathrm{N}_{00}, \mathrm{G}_{0}$ and the overall kinetics $\alpha(\mathrm{t}), \mathrm{q}(\mathrm{T})$ can be deduced directly from equation (3), where $\alpha^{\prime}(\mathrm{t})$ is defined by Avrami as the extended fraction.

$$
\alpha^{\prime}(t)=2 \pi N_{00}\left(\frac{G_{0}(T)}{q_{0}(T)}\right)^{2}\left[\frac{\left[q_{0}(T) t\right]^{2}}{2}\right]-q_{0}(T) t+1-\exp \left[-q_{0}(T) t\right]
$$

The growth rate $G(T)$ is obtained from the increase of spherulite radius as a function of time. It is supposed that nucleation is instantaneous in isothermal conditions. However, this procedure is not possible when the maximum spherulite radius is unduly small and when spherulites are too numerous. It is the case of the polyether-block amide PEBAX $^{\circledR}$.

Instead, use may be made of the light-scattering method developed by Stein and Rhodes [7]. The measurement of spherulite radius is based on the laser-scattering theory for perfect spherulites, i.e. a homogeneous anisotropic sphere in an isotropic medium. The typical scattering pattern given by a spherulitic film consists of a four-leaf clover shape, as illustrated in Figure 2. During crystallization, the pattern becomes more intense and smaller. With this method, it is possible to measure the radius $r$ of a sphere in the range of half a micron to a few microns by means of the equation (4).

$$
r=\frac{4.09 \lambda}{4 \pi \sin \frac{a \tan \left(\frac{R_{\max }}{d}\right)}{2}}
$$

$\mathrm{R}_{\max }$ is the distance from the center of the pattern to the point of maximum intensity on one lobe, and $d$ is an experimental constant.
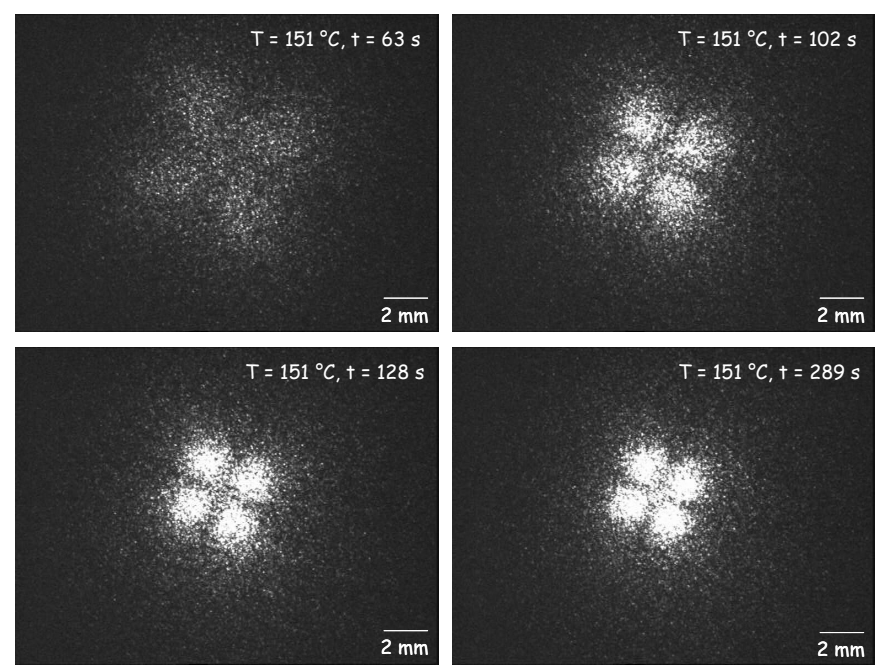

Fig. 2. Crystallization small angle laser-scattering pattern of PEBAX ${ }^{\circledR}$ in $3 \mathrm{D}(150 \mu$ m-thick layer $)$ at $151^{\circ} \mathrm{C}$ and different times t.

The confrontation of the results of $G(T(t))$ between POM and SALS is satisfactory. Respectively, it gives a growth rate of 0.1023 and $0.0939 \mu \mathrm{m} . \mathrm{s}^{-1}$ at $151{ }^{\circ} \mathrm{C}$ and of 0.0694 and $0.0664 \mu \mathrm{m} . \mathrm{s}^{-1}$ at $153{ }^{\circ} \mathrm{C}$ and of 0.0422 and $0.0587 \mu \mathrm{m} . \mathrm{s}^{-1}$ at $156{ }^{\circ} \mathrm{C}$. 


\subsection{Inverse genetic algorithm method}

In crystallization, large discrepancies are found between experimental data because of the fluctuations of the nucleation parameters which depend on the polymer and on the nucleating agents. The genetic algorithm method is applied to improve the resolution of problems linked to low precision. It is a stochastic optimization method based on the natural selection of Darwin. The optimization of the kinetic parameters is performed on the experimental evolution of the transformed volume fraction and of the number of spherulites.

\subsection{Validity of the model and Simulation in $2 D$}

The material used was the iPP. The validity of the model and the accuracy of our experimental characterization were verified. Experimental evolutions of the transformed volume fraction and of the number of spherulites as a function of the time of crystallization are correctly described by the model. Simulation of a complete injection molding cycle was performed. An as example, the injected part was a 2D plate-shaped part (thickness $8 \mathrm{~mm}$ and length $200 \mathrm{~mm}$ ). The material was injected at $230{ }^{\circ} \mathrm{C}$ and the mold temperature was $50{ }^{\circ} \mathrm{C}$. Kinetic parameters given in Table 1 refer to the equation (1) with $\mathrm{T}_{0}=$ $116^{\circ} \mathrm{C}$.

Table1. Identification of the kinetic parameters for iPP.

\begin{tabular}{lll}
\hline $\mathrm{N}_{00}\left(\right.$ in $\left.\mu \mathrm{m}^{-3}\right)$ & $\mathrm{q}_{0}\left(\right.$ in s $\left.^{-1}\right)$ & $\mathrm{G}_{0}\left(\right.$ in $\left.\mu \mathrm{m}_{\mathrm{s}} \mathrm{s}^{-1}\right)$ \\
$5.87510^{-4}$ & 0.2669 & 1.3941 \\
\hline $\mathrm{N}_{01}\left(\right.$ in $\left.^{\circ} \mathrm{C}^{-1}\right)$ & $\mathrm{q}_{1}\left(\right.$ in $\left.^{\circ} \mathrm{C}^{-1}\right)$ & $\mathrm{G}_{1}\left(\right.$ in $\left.{ }^{\circ} \mathrm{C}^{-1}\right)$ \\
0.20635 & 0.2808 & 0.1940 \\
\hline
\end{tabular}

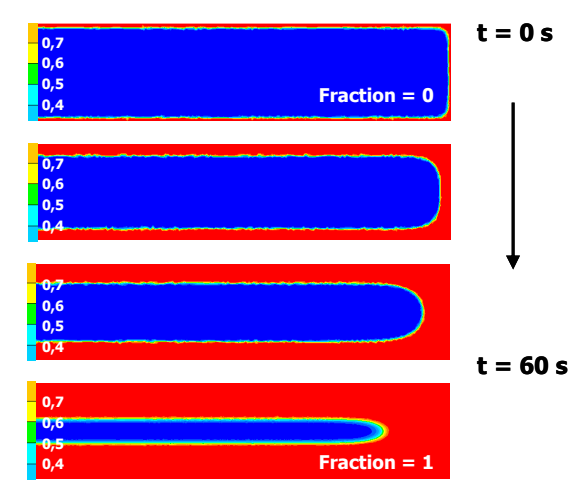

Fig. 3. Evolution of the transformed fraction distribution. Case of a cooling of a plate-shaped part.

The distribution of the transformed fraction as a function of the time of crystallization is illustrated in Figure 3. A thin solid layer appears at the borders when the calculation in $\operatorname{Rem} 3 \mathrm{D}^{\circledR}$ starts. It is due to the high cooling rate when the polymer is in contact with the mold. Then, the crystallization occurs slowly.

\section{CONCLUSIONS}

Our general differential model based on Avrami's hypotheses gives a good description of the crystallization event. It requires the identification of key kinetic parameters: initial density of potential nuclei, their activation frequency and growth rate of crystallized entities.

Optical microscopy gives access to the parameters, and can be supplemented by the laser light-scattering when growing spherulites are too small.

Optimization of the parameters is performed by means of inverse algorithm method.

It remains to gather additional experimental data that take into account the size distribution of the crystalline entities, as well as the effects of flow and high cooling rates.

\section{ACKNOWLEDGEMENTS}

The authors express their gratitude to ARKEMA for technical and financial support.

\section{REFERENCES}

1. S.A.E. Boyer, J.-P.E. Grolier, H. Yoshida, J.-M. Haudin, and J.-L. Chenot, 'Phase transitions of polymers under complex conditions', Joint Conference of JMLG/EMLG Meeting 2007 and $30^{\text {th }}$ Symposium on Solution Chemistry of Japan - Molecular approaches to complex liquids systems, Fukuoka, Japan, (21-25 November, 2007).

2. M. Avrami, 'Kinetics of phase change I', J. Chem. Phys., 7, (1939) 1103-1112.

3. M. Avrami, 'Kinetics of phase change II', J. Chem. Phys., 8, (1940) 212-224.

4. J.-M. Haudin, and J.-L. Chenot, 'Numerical and physical modeling of polymers crystallization', Intern. Polym. Process., 19 (3), (2004) 267-274.

5. J. Smirnova, L. Silva, B. Monasse, J.-M. Haudin, and J.-L. Chenot, 'Identification of crystallization kinetics parameters by genetic algorithm in non-isothermal conditions', Eng. Comput., 5 (24), (2007) 486-513.

6. L. Silva, C. Gruau, J.-F. Agassant, T. Coupez, and J. Mauffrey, 'Advanced finite element 3D injection molding', Intern. Polym. Process. 20(3), (2005) 265-273.

7. F. Van Antwerpen, and D.W. Van Krevelen, 'Lightscattering method for investigation of the kinetics of crystallization of spherulites', J. Polym. Sci.: Polym. Phys., Ed. 10, (1972) 2409-2421. 